\title{
CONTROVERSY
}

\section{Death of the general paediatrician?}

\author{
Timothy L Chambers
}

My title is adapted from that used by Professor Sir Stanley Peart in a personal paper published in $1970 .{ }^{1}$ His argument was that general internal medicine had differentiated sufficiently for there to be no place for a general physician in an academic department. There would be physicians specialising in the various body systems, relying on general practitioners (GPs) to choose the most suitable for their patients. Similar developments are taking place in UK paediatrics but I will argue that (a) there will remain an important place for the general paediatrician and (b) the specialty of general paediatrics should be recognised as one alongside others such as paediatric gastroenterology and carrying comparable esteem.

\section{Why the debate?}

Developments in medical knowledge and consumer preference mean that the traditional authority of doctors to determine the content and style of their practice is being challenged. ${ }^{23}$ Other physicians and professionals may claim that they could do a general paediatrician's job more effectively or cheaply. Paediatrics is not the only specialty where stock might be taken of its content and purpose. ${ }^{4-6}$ However the establishment of the Royal College of Paediatrics and Child Health, closer integration with Europe, and changes in primary and tertiary care in paediatrics all justify questioning the future of the generalist paediatrician.

\section{Definition}

What is general paediatrics? In the UK it is secondary care paediatrics practised by up to half a dozen specialist consultants serving a population of approximately 250000 . The position is different in most of the rest of the world. Here the general paediatrician may be a primary care physician providing services to a population similar to a UK primary care GP but seeing only children and having greater paediatric expertise. In some parts of the world the traditional primary care paediatrician is under threat, particularly from the development of family medicine which through its gate keeping functions is widely perceived as providing more cost effective care than which may obtain by direct patient access to a specialist.

The European representative body for paediatrics, the Confederation of European Specialists in Paediatrics has defined paediatrics as the medical care of the human being until the completion of growth and development. The paediatrician should therefore have a professional interest in fetuses, infants, children, and adolescents. The job of a generalist in the UK is, therefore, to diagnose on the basis of history, examination, and special investigations, and to initiate treatment that may be carried out by others under his or her supervision.

In practice this means providing a consultative service for primary care, managing as the lead physician certain conditions that are insufficiently common for the GP to manage, and identifying and referring rarer conditions which are too uncommon for the generalist to maintain familiarity and competence. Some tertiary care patients will be managed by the generalist according to guidelines agreed with the tertiary care specialist who may see the patient at local outreach clinics.

\section{What do general paediatricians do?}

They will provide general consultative outpatient clinics; they will be periodically responsible for all emergency cases referred to the department for a 24 hour period, supervising trainee paediatricians and other professionals in their diagnosis and management. They will have responsibilities for acute inpatient care of patients at all ages from infancy to adolescence and outpatient work will not only occupy them at the base hospital but may take them to outreach consultative clinics, work in schools, and other parts of the community. They will have a strong working relationships with consultants in obstetrics and gynaecology, child psychiatry, surgical specialties, general medicine and their specialties, accident and emergency consultants, and laboratory and imaging based diagnosticians.

All this work will require use of the paediatrician's brain to think, analyse, and debate. Traditionally consultant paediatricians have retained skills in practical procedures since there has been nobody else experienced enough to perform them. It is becoming increasingly questionable whether occasional operators should be expected to practise (the word is used advisedly) on their patients.

\section{SWOT and the general paediatrician}

STRENGTHS

The great advantage of general paediatricians is their breadth of knowledge and wide 
experience. They are well placed to give a good opinion about the likely cause of a patient's condition and its treatment and have a balanced approach to investigations. They are, in fact, specialists in symptomatology and its appraisal. They will have great potential in education, both for undergraduates and postgraduates undertaking general professional training and those specialists who wish to pursue a career in general paediatrics.

Although a general paediatrician may cultivate a specialist hobby it will not conflict with the proper specialist practice of a tertiary care paediatrician but may contribute to audit of such practice. Wisdom, versatility, and flexibility are, and will be, the hallmarks of the respected general paediatrician.

\section{WEAKNESSES}

Paradoxically within the greatest strength of the general paediatrician lies the greatest weakness. This is of spreading oneself too thin and not recognising one's own limitations and the potential benefits of specialist care. It could lead to inadvertent (but well intentioned) bad practice and harm to patients through failure to refer rare or complicated cases. A well tuned sense of humility is necessary. This weakness is linked to possible poor esteem both of self and by other members of the profession who may feel that specialist practice is more challenging intellectually. General paediatrics lacks both an academic base and identified specialty representation.

\section{OPPORTUNITIES}

Despite (or because of) greater public and professional education the demand for good quality paediatric care in the UK shows no signs of slacking. This provides the greatest opportunity for the general paediatrician. There is a clear need by general practitioners and the public for speedy and accessible secondary care services tailored to the needs of the child and its family rather than dictated by the preference of the doctor. This may mean the general paediatrician becoming more available at less conventional working hours (and by this I do not mean becoming resident when on call or necessarily providing hands on practical care; this could be poor use of experience).

Furthermore a wise generalist will provide skilful guidance through the maze of medical care for the child with multiple needs and in doing so may take the pressure off overburdened specialists.

An interesting opportunity may come if the UK profession is further deregulated, by allowing advertising by specialists. Insisting on primary care referral may come to be regarded as monopolistic paternalism and consumer parents of 21 st century Britain may prefer direct access to physicians specialising in child care.

The final great opportunity is the popularity of the specialty with trainees. Recruitment may have faltered because of poor and arduous working conditions but when it picks up I predict that general paediatrics will flourish. Being a jack of all trades and master of none may not be as demeaning as some think.

THREATS

However the general paediatrician must not be complacent. One threat comes from primary care. Formal vocational training in general practice has been carried out for at least 25 years. About $65 \%$ of new GP principals have held a paediatric senior house officer post. Others will obtain experience in paediatrics during their time as a GP trainee in practice. However they would never claim to be primary care paediatricians and would probably reject that notion. They are specialists in primary health care or family medicine. Rather than subtracting from the general paediatrician's practice they probably add to it by recognising conditions that need a specialist paediatrician's assessment and recommendations for management. The threat from primary care is therefore imagined rather than real; indeed in future general paediatrics may present its own threat to primary care.

There are threats to the general paediatrician from his or her own paediatric colleagues. How do general paediatricians distinguish their work from that of a community or ambulatory paediatrician, or neonatologist working at secondary care? In bigger centres the activities of intensivists may be displacing some of the work previously done by general paediatricians ${ }^{7}$ and specialist paediatricians will influence general paediatric practice.

Other specialties impinge on paediatrics, for example obstetrics and general internal medicine. Although in the past obstetricians may have undertaken neonatal practice, the paediatrician is now an active member of the team dealing with fetal health. As children with rare conditions grow up and where general medicine is not able to supply knowledgeable specialists in their diseases, paediatricians may carry on care into adult life. One brittle interface is with child psychiatry: relations between the two specialties vary from close to frosty. Each may have unrealistic expectations of the other-a situation which probably results from their exasperatingly diverse training programmes.

Other professionals might appear to threaten general paediatrics. Nurses, health visitors, psychologists, and play therapists all have a part to play in the management of the child patient. Paediatricians should welcome this and be ready to work in teams with these colleagues, always accepting that for the strictly medical aspects of care the doctor is the team leader. Parents may occasionally be treated with circumspection: their contributions are usually of great help and support. Paediatricians in future will also need to cultivate a bedside manner with the internet; half of the registrations to the Lancet website are not medical. ${ }^{8}$

The non-professional aspects of general paediatrics have threatened it in the past. Arduous on call rotas with little junior support have weakened the specialty. Our predecessors were probably too dedicated, hardworking, and tolerant. Much of this is now being remedied 
through the firm advocacy of our professional and political representative bodies. UK paediatricians work for a monopoly employer, the National Health Service (NHS). They are remunerated on a salary scale which is the same for all consultants. This development was one of the welcome changes that occurred at the founding of the NHS.

Before this paediatricians found it difficult to make a living because specialist medical care for children might have taken a lower priority in family budgets than care of the breadwinner. It remains to be seen whether the present pattern of contractual arrangements for specialists will continue. In medical political circles some have suggested that consultants will be better off if they were freelance, perhaps being employed by practices of specialists. These might be groups of the same specialty or practices of many different specialties. It seems unthinkable that the pre-NHS philosophy of 'children last' would re-emerge and it is most likely that present demands for paediatric care will continue and that paediatricians will be seen as a valuable part of the specialist medical repertoire.

However this cannot be taken for granted and if employment conditions for consultants change our political representatives - and particularly those for the general paediatricianwill have to be vigilant. Private paediatric practice in the UK presently represents a tiny minority of health care activity: it is unlikely to be a major factor in recruitment. Furthermore few general paediatricians perform procedures - endoscopy - which attract greater renumeration. Inpatient paediatrics is not easy to organise outside London. Some paediatricians disapprove of private practice, feeling it offers two standards of care. If contractual arrangements change they may need to modify their views. Fierce commercial competition could be damaging to general paediatrics, sandwiched between the primary care doctor, the specialist paediatrician, and others.

There can be few paediatricians who have not been affected by civil legal processes, either because claims have been made against them, alleging negligent practice or they have been involved as expert advisors. Litigation is probably a minor threat to the general wellbeing of paediatrics; however general paediatricians should not be complacent and should maintain the high standards of medicine, documented in clear records and communicated fully and sensitively to patients and parents.

\section{On balance?}

Although the weaknesses and threats are clear, in my view the strengths and opportunities for the general paediatrician are more powerful. Furthermore medical practice is changing; the use of information technology to aid diagnosis, the education of both doctor and patient about various medical conditions and the best evidence for their treatment, and its possibilities in continuing medical education could mean that the generalist might have a rosier future than is presently foreseen.
After all it is patients we manage not conditions. The basis for development of many specialties has been technical. If professionals other than doctors undertake those techniques, under the professional supervision of doctors, then it may be the specialties which are threatened as much as the generalist.

\section{Representation of general paediatrics}

In the UK the general paediatrician will be a member or fellow of the Royal College of Paediatrics and Child Health which will have oversight for postgraduate training and continuing medical education. Its predecessor, the British Paediatric Association (BPA), started as a specialty group for general paediatricians. Over the last 20 years the development of specialty paediatrics, community paediatrics, and neonatal medicine have seen the establishment of specialist societies catering for those specialists. The very success of the BPA, the college, and the specialist societies may have threatened the professional representation and colleagueship of the general paediatrician. The Royal College of Physicians of London has a committee on general internal medicine alongside its committees on respiratory medicine, cardiology, etc. I believe the interests of general paediatrics would be enhanced by a similar arrangement. This would be important if academic development occurred. General paediatricians have other more informal educational groupingsvisiting clubs, the Royal Society of Medicine, and the Cambridge summer meeting.

Political representation of paediatricians in the UK has been mainly through the British Medical Association. The consultants representative committee has had a paediatric subcommittee for many years and, working closely with the BPA and the royal colleges it has defended the interests of general paediatricians over contracts, remuneration, and in disputes with employers. In representational terms therefore general paediatrics has great strengths both professionally and politically to support it. It must, however, be clear what the specialty is and why it merits such support.

\section{Training and education}

The Specialist Advisory Committee in paediatrics (now the Training Committee of the Royal College of Paediatrics and Child Health) has thought hard about the professional and technical attributes of a general paediatrician; these will change following the pattern of practice and with developments in specialist education. When devising training programmes comprehensiveness is reassuring-one can check through a list of requirements and be satisfied that one has met them. To do so however would produce a one dimensional paediatrician.

The most important criteria are openmindedness, strategic thinking, team working, communication, and an ethical approach to doctorpatient relationships. Keeping up to date and practising high standards in medicine (including continuity of care) are cornerstones of successful and enjoyable consultant practice. Lists of skills are a helpful guide but the wise trainee 
will chose one or two mentors to help them through their training programme and also to review how they are developing the subtler but more important skills of a respected general paediatrician. Perhaps the most important thing one learns in postgraduate training is that one is never fully trained and that patients continue to teach lessons until retirement. The elusive skill is to be able to recognise when one is being taught.

\section{Academic general paediatrics}

Many occupants of university chairs of paediatrics and child health are specialists in some field of paediatrics. Among their many other duties they may have responsibility for acute paediatric beds or may be on take. However general paediatrics has not developed its academic backbone to the same extent as the organ specialties in the UK. This is regrettable but understandable. If general paediatrics is to claim parity of esteem with the organ specialties then it must develop its academic strength.

It is here that the interface with ambulatory and community paediatrics becomes so important and a strong case could be made for combining all these activities under the rubric of general paediatrics. Much is heard of the new morbidity that children face now that deaths from traditional epidemic conditions are becoming rarer. This new morbidity deals with many matters (behavioural, developmental, psychological) which are common to general and community paediatrics; although their academic background may be in operational rather than basic research, there are still many questions to be answered. Academic strengths could also be drawn from alliance with departments of primary care in tackling questions which are of pressing importance to large numbers of children - for example the aetiology and management of glue ear, attention deficit and hyperactivity, and chronic fatigueand may be of comparable individual and social burdens to organ failure. The great disadvantage of academic specialisation is its fragmentation. For the clinical application of basic scientific knowledge patients' interests may be served better by some unification of specialist care, heralding the renaissance of the generalist.
Rebirth of the general paediatrician? Some years later Peart recanted. ${ }^{9} \mathrm{He}$ used as an example a clinical case of a patient with serious problems affecting many different body systems. He recognised that such patients need wise, skilled, and experienced specialist doctors to help them face the multiple trials that such conditions present. Such doctors do not supplant the specialists but are complementary to them. At its best such an approach really does treat a patient rather than diseases. I would not go as far as some hospitals in continental Europe which insist that all patients are admitted under the care of general paediatricians who perform a coordinating role with the various specialists - or would I? It is particularly important that tertiary centres (particularly Great Ormond Street Hospital) recognise the importance of the generalist and appoint at least one to their staff. They can also provide opinions on difficult or unclassifiable cases for generalist colleagues and deal with the local unsorted general work. These are responsibilities that can not be carried by our colleagues in primary care. Their interest and experience is essentially wider. Providing the nerve of general paediatrics (and its leaders) holds, suitable specialist alliances forged and academic and representational presences created, then I believe that general paediatrics has a sound and attractive future and will attract the best of medical graduates. Floreat general paediatrics! Vivat the general paediatrician!

This paper is based on a presidential address to the Section of Paediatrics, Royal Society of Medicine.

1 Peart WS. Death of the professor of medicine. Lancet 1970;i:401-2.

2 Anonymous. Tomorrow's doctoring-patient heal thyself. The Economist 4th February 1995:19-21.

3 Anonymous. Why doctors? The Economist 10th December 1994:117-8.

4 Bennett G. What should psychiatrists be doing in the 1990 s? BMF 1988;296:274-5.

5 van Wheal C. Primary care: political favourite or scientific discipline? Lancet 1996;348:1431-2.

6 Bennett JR. The general physicians-dinosaur or superman? F R Coll Physicians Lond 1997;31:6-7.

7 Burke BL. The paediatrician's role-shrinking and shrinking. Pediatrics 1996;98:1222-3.

8 Anonymous. Goodbye to all that [Editorial]. Lancet 1996;348:1671.

9 Peart WS. Rebirth of the professor of medicine. Lancet 1983;ii:810-2. 